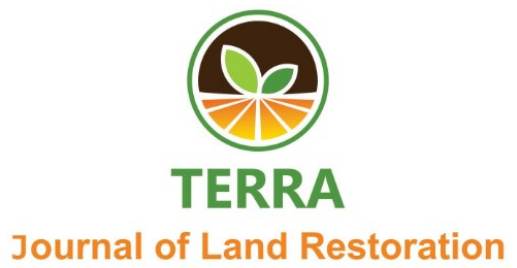

\title{
A Model to Predict Plant-available Water Content of Soils at Different Land Units in Bengkulu, Indonesia
}

\author{
Bandi Hermawan $^{1}$, Hasanudin ${ }^{1,2}$, Indra Agustian ${ }^{3}$, Bambang Gonggo Murcitro ${ }^{1}$ \\ ${ }^{1}$ Soil Science Department, University of Bengkulu (Corresponding author) \\ ${ }^{2}$ Member of Computer and Information Service Board, Bengkulu University, Bengkulu, Indonesia \\ ${ }^{3}$ Department of Electrical Engineering, Faculty of Engineering, Bengkulu University,Bengkulu,Indonesia \\ e-mail: bhermawan@unib.ac.id
}

\begin{abstract}
Soil water availability to the plants is a very important physical property of soil that controls water and nutrient absorption by the plant. It is defined as the difference between the maximum amount of water the soil can hold and the minimum condition that the plant can no longer extract water from the soil. However, soil factors that control the plant available water content (PAWC) in the soil have not been fully understood. The present study aims to analyze the relations between particle-size distributions and organic carbon with the available water of the soil and to develop a model of predicting PAWC. Five soil profiles at different land units were described up to the depth of 100 $\mathrm{cm}$. Ten undisturbed soil samples were taken using the stainless-made core sampler from $10 \mathrm{~cm}$ increments for the soil water holding capacity analysis. A similar number of disturbed samples were also provided from the same depths for soil texture and organic carbon analysis. Results showed that the variance in PAWC could be explained by sand and clay fractions $\left(R^{2}>0.35\right)$ but not by silt and organic carbon contents. Therefore, we were able to develop a model for the prediction of available water content in the soil from the sand and clay parameters. The model will help decision-makers be able to propose conservation and management strategies for PAWC in agricultural practices as well as for the soil moisture retention at civil works.
\end{abstract}

Keywords: water content; model; soil profiles

\section{INTRODUCTION}

Sustainability of soil management practices depends on soil hydraulic properties such as the available water content for the plant growth. The plant-available water content (PAWC) is a very important physical property of soil that controls water and nutrient absorption by the plant. It is defined as the difference between soil water content at the field capacity where the maximum amount of water the soil can hold and at the permanent wilting point representing the minimum condition the plant can no longer extract water from the soil. Several references emphasize that PAWC depends on the climate changes that control the available water supply (Littke et al., 2018) and soil factors responsible for the water holding capacity (Hillel, 1980). The climate change factors that influence the amount of available water in the soil include monthly precipitation and air temperature, therefore, they are used to predict the available water supply in the soil profile. The effects of climatic variables on temporal changes in the plant-available water are more significant for the shallow soils due to the limited capacity of soil profile porosity in holding the water. In the steep lands that suffered from gully erosion, a combination of storm events and slope positions is responsible for spatiotemporal variations in the available soil water content as reported by Sadeghi et al. (2019).

Soil factors play an important role in balancing water status in the soil profile, storing the water during the rainy season and supplying it to the plant in the dry condition. Soil physical properties, in particular, determine the amount of water that remains in the soil profile following precipitation or irrigation application, as well as provide the soil water to be available for the plant growth. In the water balance prediction using Richard's equation (Rong, 2012), soil physical properties are often used to calculate water-holding capacity (WHC) as a variable for the available water calculation, since the direct 
measurement of PAWC is very costly. Soil properties related to PAWC can be grouped into those affecting water loss from the soil surface and plant by evapotranspiration and gravimetric forces by deep percolation (Blaschek et al., 2019). When combined with climatic variables, soil factors will control the amount of water remaining in the soil profile during the growing season.

However, soil factors that strongly control the PAWC in the soil have not been fully understood and fewer studies have been conducted on this issue. A study by Román Dobarco et al. (2019), for example, used sand, clay, soil organic carbon, and bulk density of soils as predictor variables for PAWC but the results only covered less than half of existing horizons in the study area. Better uses of soil factors as PAWC predictors were reported by De Paepe et al. (2018) in which soil properties at the surface $0-20 \mathrm{~cm}$ layer provided good estimates of profile PAWC up to the depth of $140 \mathrm{~cm}$. The later study could be interpreted and applied to minimize the number of sampling and laboratory works in calculating PAWC at the deeper soil profiles. Therefore, further research is required to find out soil properties that strongly related to PAWC and use them as predictors in the PAWC model.

The present study aims to analyze the relations between particle-size distributions and organic carbon with the PAWC of the soil and to develop a model of predicting the availability of soil water. It is assumed that at least one of the proposed variables will strongly be related to and can be used as predictors in the model of PAWC calculation in the soil.

\section{MATERIAL AND METHOD}

\section{Description of study areas}

The research was conducted at young and mature oil palm and rubber, respectively, as well as horticultural plantations in North Bengkulu Regency, Bengkulu Province, Indonesia during the soil water discharged period of April to September 2019. The altitudes of five soil sampling and measurement sites ranged from 25 to $500 \mathrm{~m}$ above sea levels at the geographical positions of $102^{0} 09^{\prime} 55.0^{\prime \prime}$ to $102^{0} 27^{\prime} 01.7^{\prime \prime}$ $\mathrm{E}$ and $03^{0} 277^{\prime} 34.6^{\prime \prime}$ to $03^{0} 36{ }^{\prime} 30.5 " \mathrm{~S}$. During the study period, monthly precipitation decreased from 278 in April to $3 \mathrm{~mm}$ in September for the lowland, and from 843 to $45 \mathrm{~mm}$ at the same period for the highland sites. Sampling sites were located in five plantation areas in North Bengkulu Regency, including mature and young rubber, mature and young oil palm, and fruit farm.

The study sites had different soil profile characteristics, the A-horizon thicknesses ranged from 7 to $50 \mathrm{~cm}$, the B-horizon from 35 to $90 \mathrm{~cm}$, the surface soil structures of granular in the oil palm and rubber sites and blocky in the cultivated fruitland. Soil colour varied with the land use, ranging from yellowish-brown (10 YR 5/8) to dark (5 YR 1/1) in the A horizon and reddish yellow $(7,5 \mathrm{YR} 6 / 6)$ to brown $(7,5$ YR $5 / 3)$ in the B horizon indicating the different distribution patterns of soil organic carbon with depth. Soil texture also varied obviously with soil depths as indicated by the soil consistency that ranged from weak to moderately strong under moist conditions.

\section{Model development}

In mathematical modeling, the dependent variables are tested, for example using the regression and correlation analysis, to see if and how much they vary as the independent variables vary. The independent variables refer to input while the dependent variables to the output of the mathematical model. In the current study, we developed a variable-intervening model to predict the soil PAWC as a dependent variable as described in Figure 1. Variable PAWC (Y) was a direct product of two soil properties such as water content at the field capacity and permanent wilting point conditions $\left(\mathrm{Y}_{1}, \mathrm{Y}_{2}\right)$, in which $\mathrm{Y}=\mathrm{Y}_{1}-\mathrm{Y}_{2}$. Adopting variables used by Román Dobarco et al. (2019), three soil fractions (sand, silt and clay content) and organic carbon content (variables $\mathrm{X}_{1}, \mathrm{X}_{2}, \mathrm{X}_{3}, \mathrm{X}_{4}$, respectively) were then correlated with variables $Y_{1}$ and $Y_{2}$. Strongly related independent variables with the water holding indicators of $Y_{1}$ and $Y_{2}$ were used as the predictors in the soil PAWC model.

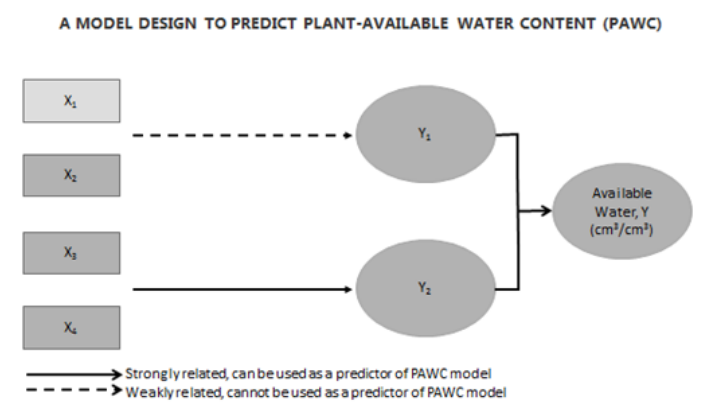

Figure 1. Design of model development to predict PAWC from soil variables

\section{Sampling and measurements}

Five soil profiles at different land units were dug to the depth of $100 \mathrm{~cm}$ then described in the field to identify layers of soil horizons as well as the basic physical characteristics at each soil horizon layer. Ten undisturbed soil samples were taken from each profile using the stainless-made core sampler of $5.0 \mathrm{~cm}$ diameter and $4.0 \mathrm{~cm}$ height at $10 \mathrm{~cm}$ 
depth increments. Undisturbed soil samples were used for the laboratory analysis of soil water retention variables using the pressure plate apparatus set at 0.35 and 15 bars. Both pressures resulted in the volumetric water content under the field capacity and permanent wilting point conditions, respectively. Soil bulk density was also measured at a corresponding depth to calculate the temporal volumetric based on gravimetric water content. A similar number of disturbed samples were also provided from the same depths for the particle-size distribution (Hydrometer Method) and organic carbon analysis (Walkley-Blacky Method).

Gravimetric water content was measured periodically at each sampling site using the dielectrometer device (Hermawan et al., 2017) at $10 \mathrm{~cm}$ depth intervals to a total of $100 \mathrm{~cm}$. Soil bulk density data were multiplied with the gravimetric water content at the corresponding layer to calculate the volumetric water content. The proposed model was then applied to evaluate temporal variations in the volumetric water content in comparison to predicted PAWC of study soils.

\section{Statistical analyses}

Relations between independent and dependent variables will be analyzed using the regression equation and correlation techniques. Independent variables that had a relatively strong relation $\left(\mathrm{R}^{2}>0.35\right)$ with PAWC were used as the predicting variables in the model.

\section{RESULT AND DISCUSSION}

\section{Relations between variables}

Sand and clay fractions had strong relations $(\mathrm{R}>0.50)$ with soil water content at the field capacity condition (Table 1) although both variables were less related to that at the permanent wilting point status. Since the soil PAWC was calculated from the difference between soil water content at the field capacity and the permanent wilting point, both soil fractions also had good relations with PAWC. The results agreed with other studies that the availability of soil moisture to the plant was strongly effected by clay content (Sani \& Alhassan, 2019) and sand fractions (Chertkov, 2010). In the current study, silt and organic carbon content had weak relations $(\mathrm{R}<0.25)$ with water content at the field and permanent wilting point conditions hence with the soil PAWC. Overall, soil factors only had close relations to the field capacity water but not to the permanent wilting point water suggesting that the relations occurred in the interaggregate macropores rather than in the withinaggregate micropores.
Table1. Coefficient of correlations (R) between four independent and two water holding variables.

\begin{tabular}{lcc}
\hline \multicolumn{1}{c}{ Independent Variables } & Field Capacity & Permanent Wilting Point \\
\hline Sand fraction (\%) & $\mathrm{R}=0.59 ; \mathrm{N}=50$ & $\mathrm{R}=<0.25 ; \mathrm{N}=50$ \\
Silt fraction (\%) & $\mathrm{R}=<0.25 ; \mathrm{N}=50$ & $\mathrm{R}=<0.25 ; \mathrm{N}=50$ \\
Clay fraction (\%) & $\mathrm{R}=0.66 ; \mathrm{N}=50$ & $\mathrm{R}=<0.25 ; \mathrm{N}=50$ \\
Organic carbon content (\%) & $\mathrm{R}=<0.25 ; \mathrm{N}=50$ & $\mathrm{R}=<0.25 ; \mathrm{N}=50$ \\
\hline
\end{tabular}

Note: shadowed boxes indicated predictors of the model.

\section{Model to predict plant-available water}

Results of regression and correlation analyses presented in Table 1 indicated that the coarse sand and fine clay fractions could be promoted as the independent variables in predicting soil PAWC. The relations between sand and clay content with soil PAWC were used to construct the variable-intervening model as proposed in Figure 2. In this model, sand and clay were used to calculate the field capacity water content and use it to predict the PAWC by assuming the value of water content at the permanent wilting point was known and constant at different texture classes. According to the model, soil PAWC increases by $0.0015 \mathrm{~cm}^{3} / \mathrm{cm}^{3}$ and decreases by 0.002 $\mathrm{cm}^{3} / \mathrm{cm}^{3}$ following increases in $1 \%$ of sand and clay percentage, respectively. The proposed texture-based model found in the current study was similar to an earlier study that the sand-silt-clay combined model showed predicted soil PAWC, bulk density, and porosity at several soil textures (Zartman, 2006).

The model shown in Figure 2 needed further studies in other regions of Bengkulu areas since the variations in soil PAWC could only be explained by about $36\left(\mathrm{R}^{2}=0.36\right)$ and $44 \%\left(\mathrm{R}^{2}=0.44\right)$ of sand and clay content, respectively. There were at least $20 \%$ of variations in soil PAWC that could be explained by other soil characteristics rather than sand and silt fractions. Soil bulk density was a variable that could be considered in the future studies of modeling soil PAWC. A study by Li et al. (2016), for example, included soil bulk density in the texture -based prediction of soil PAWC in the oasis-dessert transect of China. Another study by Qiao et al. (2019) discussed more detail about relations of texture and bulk density to soil PAWC, in which the sand fraction was more related to the field capacity water while the clay content and bulk density to the permanent wilting point. Before applying the proposed model to a wide range of regions, it required a calibration by testing data collected from other sites. 


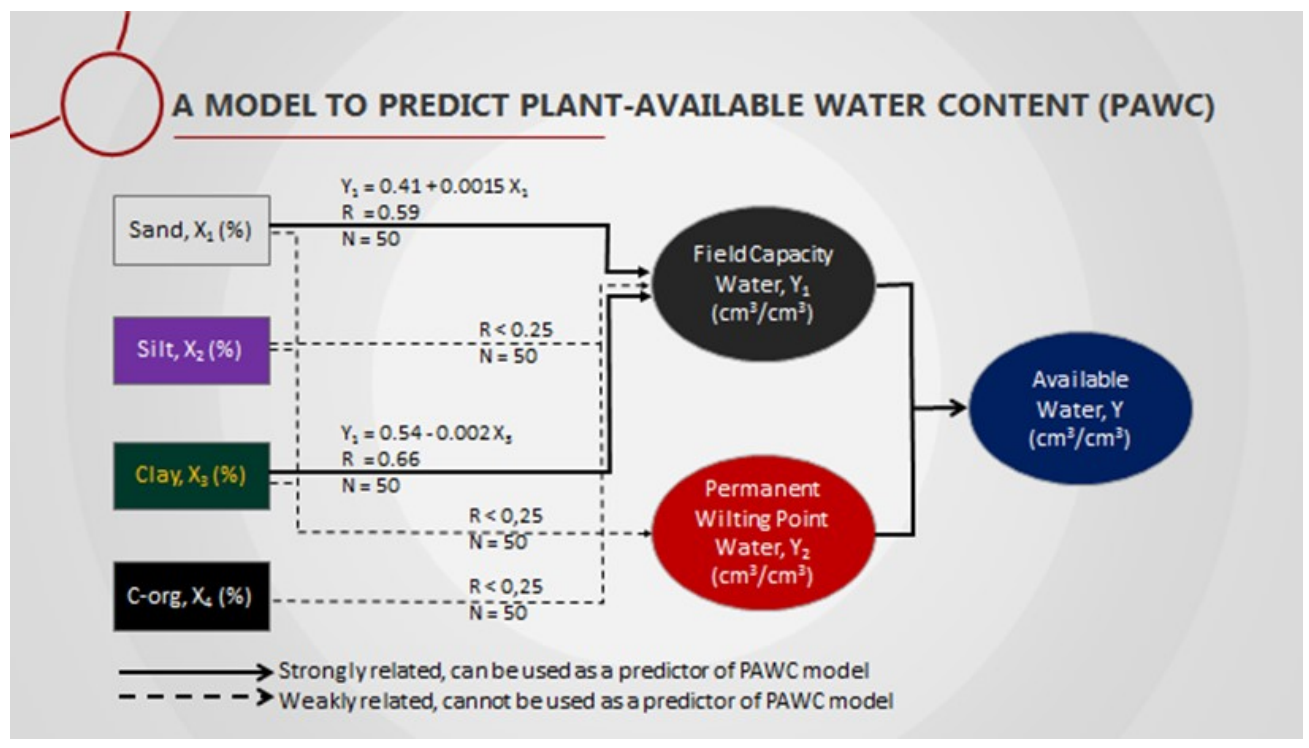

Figure 2. A model to predict soil PAWC from sand and clay fractions

The accurate model for PAWC prediction would be a solution for cheap and quick determinations in many field applications such as the prediction of grain yield of crops (Al-Khafaf, 1988) as well calculation of water retention for engineering works involving sites with high soil suction ranges (Wang et al., 2019).

\section{CONCLUSION}

The plant-available water content (PAWC) of soils could be predicted from sand and clay fractions $(\mathrm{R}>0.59)$ but not from silt and organic carbon contents. The sand and clay relations to soil PAWC were pronounced with the field capacity water, as a component of soil PAWC, rather than with the permanent wilting point. Therefore, we were able to develop a model for the prediction of available soil water content from the sand and clay parameters. The model will help decision makers be able to propose conservation and management strategies for PAWC in agricultural practices as well as for the soil moisture retention at civil works.

\section{Declaration of competing interests}

The authors declare that they have no known competing for financial interests or personal relationships that could have appeared to influence the work reported in this paper.

\section{Acknowledgment}

This research was fully funded by the Directorate of Research and Community Service, Ministry of Re- search, Technology and Higher Education Republic of Indonesia, Contract No: 165/SP2H/LT/DRPM/ 2019.

\section{References}

Al-Khafaf, S., Al-Awad, M.C.\& Adnan, A. (1988). A model for predicting crop yield from threshold limits of available soil water. Journal of Agriculture and Water Resources Research. Soil and Water Resources (Iraq), 7(1), 33-46.

Blaschek, M., Roudier, P., Poggio, M. \& Hedley, C.B. (2019). Prediction of soil available waterholding capacity from visible near-infrared reflectance spectra. Scientific Reports, 9(1), 110.

Chertkov, V.Y. (2010). Water retention of rigid soils from a two-factor model for clay. The Open Transport Phenomena Journal, 2, 90-102.

De Paepe, J.L., Angel Bono, A. \& Alvarez, R. (2018). Simple estimation of available water capacity in soils of semiarid and subhumid environments. Arid Land Research \& Management,32 (2),133.http://e-resources.pepusnas.go.id: 2077/login.aspx?direct $=$ true $\& d b=e d b \& A N=$ 128104166\&site $=e d s$ - live. Accessed March 25, 2020.

Hermawan, B., Suparjo, E., Hindarto, K.S., Silalahi, R. \& Barchia, F. (2017). A quick dielectric method to determine in-situ soil water content for precision water use under sustainable agricultural practices. International Journal on Advanced Science Engineering Information Technology, 7(3), 910-915.

Hillel, D. (1980). Introduction to Soil Physics. Academic Press, Inc., London, Toronto. 
Li, D., G. Gao, Shao, M. \& Fu, Bojie. (2016). Predicting available water of soil from particlesize distribution and bulk density in an oasisdesert transect in northwestern China. Journal of Hydrology, 538, 539-550.

Littke, K.M., Zabowski, D., Turnblom, E. \& Harrison, R.B. (2018). Estimating shallow soil available water supply for Douglas-fir forests of the coastal Pacific Northwest: climate change impacts. Canadian Journal of Forest Research, 48(4), 421-430.

Qiao, J., Y. Zhu, X. Jia, Huang, L. \& Shao, M. (2019). Pedotransfer functions for estimating the field capacity and permanent wilting point in the critical zone of the Loess Plateau, China. Journal of Soils \& Sediments: Protection, Risk Assessment, \& Remediation, 19(1), 140-147.

Román Dobarco, M., Cousin, I., Le Bas, C. \& Martin, M.P. (2019). Pedotransfer functions for predicting available water capacity in French soils, their applicability domain and associated uncertainty. Geoderma, 336, 81-95. DOI: http://10.1016/j.geoderma.2018.08.022.
Rong, Y. (2012). Estimation of maize evapotranspiration and yield under different deficit irrigation on a sandy farmland in Northwest China. Afr. J. Agr. Res. 7, 4698-4707.

Sadeghi, S.H., Ghaffari, G.A., Rangavar, A., Hazbavi, Z. \& Sing, V.P. (2020). Spatio temporal distribution of soil moisture in gully facies. International Soil and Water Conservation Research, 8(1),15-25.DOI:https://doi.org/10.1016/j.iswcr. 2019.10.001.

Sani, M. \& Alhassan, I. (2019). Influence of soil depth and texture on moisture characteristics and plant available water content of Alfisols in northern Guinea Savannah of Nigeria. Azarian Journal of Agriculture, 6(4), 80-85.

Wang, L., Zhang, W. \& Chen, F. (2019). Bayesian approach for predicting soil-water characteristic curve from particle-size distribution data. Energies, 12(15), 2992.

Zartman, R. (2006). Soil Texture and Water Management. American Nurseryman, 203(5), 32-34. 